\title{
EL RINCÓN DE LOS BICHOS RAROS: FRANZ KAFKA Y EL CASTIGO EN LA METAMORFOSIS
}

\author{
NiCOLÁS LAZO JEREZ* \\ Universidad Alberto Hurtado
}

\begin{abstract}
RESUMEN: El ensayo pretende abordar la noción de castigo al interior del relato más célebre de este escritor checo. Se sugiere que, si bien no existe certeza respecto a los simbolismos - de haberlos- que encierra la obra, cabe suponer un comportamiento sancionador en el trato de los demás actores hacia el personaje central, motivado por la inutilidad y progresiva alienación que este último exhibe. Asimismo, se relativiza la versión según la cual el texto corresponde a un testimonio autobiográfico de Kafka, aun cuando se distinguen elementos procedentes de su propia experiencia.
\end{abstract}

Palabras clave: transmutación, marginación, castigo, condena.

ABSTRACT: The essay tries to approach the notion of punishment to the interior of the most famous statement of this Czech writer. It is suggested that, though certainty does not exist with regard to the symbolisms - if there are - that encloses the work, it is necessary to suppose a sanctioning behavior in how other actors act towards the central character motivated by the uselessness and progressive alienation that the latter exhibits. Likewise, there is relativized the version according to which the text respondes to Kafka's autobiographical testimony, even if there are distinguished elements proceeding from his own experience.

Key words: transmutation, exclusion, punishment, sentence.

Llevar a cabo una reflexión que sitúe la noción de castigo dentro del campo literario se presenta, a primera vista, como una tarea no demasiado compleja. Por un lado, abundan las obras cuya temática principal es, precisamente, la de la sanción en cualquiera de sus formas, con Crimen y castigo, de Fiódor Dostoievski, como uno de los casos más visibles del último siglo y medio. Por otro, el ejercicio mismo de la escritura se ha visto permanentemente vinculado tanto a la restauración psicológica como al desahogo tras -o durante- cierto padecimiento, resultado o no de una falta cometida. Juan José Millás, por ejemplo, recuerda a su padre cortando carne con un bisturí eléctrico y emitiendo al respecto un comentario que, a juicio del novelista español, resulta perfectamente comparable al acto de escribir: "Fíjate, Juanjo, cauteriza la herida en el momento mismo de producirla" ${ }^{1}$. Sin embargo, dar con una descripción minuciosa, descarnada, conmovedora, profunda y a la vez sintética -si bien ficticia- de la experiencia en que hay sanción ya no parece tan sencillo.

Existe, un relato de fama universal donde tal testimonio efectivamente se ejecuta, aunque de un modo en especial impreciso: se narra el castigo junto a sus múltiples fuentes posibles y, de modo simultáneo, no es aludido directamente como tal, de manera que no puede sostenerse con absoluta seguridad que entre las intenciones del autor haya estado

\footnotetext{
* Estudiante de Licenciatura en lengua y literatura, Universidad Alberto Hurtado de Santiago de Chile

${ }^{1}$ Millás, Juan José. El mundo. -1 ra edición- Buenos Aires, Argentina: Planeta, 2007, p. 8.
} 
desarrollar un discurso en esa línea. En cuanto a esto último, por lo tanto, conviene aclarar desde ya que, lo que el presente ensayo propone, corresponde más bien a una entre múltiples lecturas posibles y no a una pretensión explícita de la obra.

\section{EL BICHO RARO}

En 1912, Franz Kafka redacta algo así como una nouvelle de estilo y fondo tan particulares que, según el propio Vladimir Nabokov, se trataría del "mejor relato que produjo todo el episodio de las letras contemporáneas". El texto, de no más de ochenta páginas, refiere la historia de Gregor Samsa, un vendedor viajero que, como sabemos, cierta mañana al despertar se enfrenta al hecho inexplicable de hallarse convertido en una criatura parecida a un escarabajo. Tratándose de una trama simple -al menos en apariencia-, lo que ocurre de ahí en adelante no son sino los resultados de ese primer acontecimiento inusual en el protagonista y su familia: negación, espanto, perplejidad, rechazo instintivo, asco, violencia, hábito paulatino ante la nueva situación, indiferencia, abandono, otra vez violencia y, finalmente, la muerte.

Bajo una primera lectura, bien puede sugerirse que, si acaso hay presencia de una sanción, esta se manifiesta a través de la aversión que despierta el personaje central dado sus nuevas características físicas: como efecto de una espontánea respuesta agresiva ante aquello que contraviene todo esquema mental, se rehúye de lo desconocido y, de haber algún tipo de control sobre lo que en este caso es, encima, un animalejo monstruoso y repulsivo, el trato que se le propina da cuenta de la poca tolerancia acostumbrada frente a fenómenos de su tipo. En efecto, todo aquel que lo ve -el gerente de la empresa en que trabaja, los huéspedes que, en vista de las urgencias económicas, habitan un cuarto del piso- reacciona con horror y repulsión, e incluso la madre, que es por otra parte quien mayor aflicción exhibe, nunca cesa de experimentar ambas sensaciones en presencia del transformado Gregor. No obstante, nadie se detiene mucho en el hecho inverosímil de que un miembro de la familia Samsa no solo haya cambiado de forma, sino que además lo hiciera -involuntariamente, como es obvio- para convertirse en una suerte de insecto gigantesco. El fenómeno, por cierto, afecta a sus circundantes; les irrita o entristece, alternativamente, durante largo tiempo. Con todo, se lamentan de la manera en que lo haríamos respecto a la enfermedad terminal de un ser querido. En ningún momento los oímos preguntarse cómo es posible tamaña irracionalidad. Así, cabe desestimar una idea de castigo reflejada en una violencia producida por la perplejidad.

En segundo lugar, aparecen como elementos relevantes las consecuencias prácticas de las nuevas circunstancias. Gregor Samsa, debe recordarse, es el sustento económico de un grupo familiar compuesto por un padre jubilado, un ama de casa y una muchachita -Grete- cuya vida, hasta ahora, ha consistido en tocar el violín y colaborar mínimamente en las labores domésticas. Con el nuevo escenario, en cambio, el padre se ve en la necesidad de volver a trabajar y ejerce como empleado subalterno en un banco, actividad que, por lo demás, le devuelve energía al cuerpo e inclusive algo de autoridad; la madre cose ropa interior de lujo para una tienda de modas; la hermana, junto con trabajar como 
vendedora, estudia de noche taquigrafía y francés, "quizá para conseguir más tarde algún puesto mejor" 2 . No solo eso: también venden las joyas, despiden a la criada y, como ya se dijo, alquilan una de las habitaciones. De este modo, la inesperada situación da pie a un descalabro económico y un desmoronamiento moral; el protagonista siente vergüenza, considera que desde cierto punto de vista tiene un grado de culpa en la suerte que han corrido los suyos. Sus padres y hermana, agotados con tanto afán, poco a poco van restándole importancia a este error $-\mathrm{u}$ horror- que el azar quiso endosarles. Ya no hay tiempo para casi nada: que la desagradable criatura, auténtico lastre dado las actuales premuras, se las arregle como mejor pueda. La perspectiva según la cual los demás castigan la inutilidad $-y$, con esto, al ahora extraño que falló en la función que le correspondíaluce, entonces, fundamentada con los acontecimientos del relato.

\section{GREGOR KAFKA, ESCARABAJO}

En numerosas ocasiones se ha planteado la posibilidad, aparentemente evidente, de que la figura principal de esta obra cumbre sea una especie de trasunto del autor. Este último, de acuerdo a lo que uno de sus editores -Jordi Llovet- indica en un prólogo a la narración, hizo notar la coincidencia partiendo por la semejanza en los apellidos: "[...] en conversación amigable con Gustav Janouch, manifestó: 'El protagonista de la narración se llama Samsa. Suena como un criptograma de Kafka. En ambos casos hay cinco letras. La $S$ en la palabra Samsa ocupa los mismos lugares que la $K$ en la palabra Kafka'" 3 . Si a esto añadimos que, al igual que el comerciante devenido en escarabajo, Kafka mantenía a su familia con un muy poco estimulante empleo y declaraba, según consta en su correspondencia, cierto aprisionamiento en la rutina diaria, las similitudes no parecen pocas ni desdeñables.

Dicho lo anterior, habría que preguntarse entonces: ¿qué significación simbólica podría tener la transformación en el autor que nos ocupa? ¿Es que acaso Kafka se sentía víctima de las tensiones que aquejan a Gregor Samsa? Llevando la idea al extremo: ¿se veía a sí mismo como un insecto? En el evento de que nos guiáramos por la imagen que, con el transcurso de los años, la cultura popular ha construido de él, tendríamos que responder afirmativamente. Cierto intérprete madrileño, por ejemplo, interpela a un(a) interlocutor(a) invisible en una canción donde detalla su reciente estado de desánimo, señalándole que ha dejado su amor propio "por debajo del de Kafka", como si este fuese ya un referente de la baja autoestima. Varias otras voces de las más diversas procedencias, en tanto, insisten en perfilar al escritor como una persona atormentada por los hechos de su tiempo y sus circunstancias personales -cuerpo enfermizo, relaciones amorosas inestables: poeta maldito que no vio jamás la luz del día-.

Más allá de las caricaturas que puedan haberse creado, lo cierto es que no todas estas apreciaciones son exageradas. Los biógrafos nos han informado, gracias -nuevamen-

\footnotetext{
2 KAFKA, Franz. La transformación. -1 ra edición- Buenos Aires, Editorial Sudamericana, 2006, p. 74.

${ }^{3}$ KAFKA, Franz. op. cit. (n. 2), p. 12.
} 
te- a los escritos de carácter íntimo, que Kafka sufría enormemente la contradicción vital entre el deseo de mantener vínculos normales y la necesidad de soledad y silencio que implicaba el ejercicio de su escritura. Más aún; la figura de su padre, lejana y autoritaria, siempre resultó un foco de conflictos no resueltos que, si damos al relato una revisión autobiográfica, se repiten en la trama del mismo y llegan a su punto máximo cuando el señor Samsa repele a su hijo lanzándole manzanas, una de las cuales se incrusta en el caparazón de Gregor. Pese a ello, ¿hasta qué punto podemos llevar esta confusión entre autor y narrador y la tesis más bien improbable de que se trata de un testimonio individual? ¿Cómo contradecir la opción, mucho más factible, de que La metamorfosis no es sino una pieza -fantástica a la vez que terrorífica- cuyos materiales, solo algunos, están extraídos de la realidad, y que quizás - solo quizás- no oculta nada tras los sucesos referidos? Para bien o para mal, no existe una respuesta definitiva a esto. El trabajo interpretativo, con su debida argumentación, concierne a los críticos.

Otra lectura frecuente tiene una inspiración religiosa. En el antiguo testamento -otro conjunto de relatos, el más famoso tal vez, donde la noción de castigo tiene una presencia transversal- pueden distinguirse dos formas de "procedimiento penal", las cuales, en casi todas las ocasiones, son respuesta a una transgresión de la ley divina y/o moral. La primera -juicio o mispat-, comprende la acción de un victimario malvado y prepotente, una víctima generalmente indefensa y un tercer sujeto -Dios- que, en palabras del teólogo jesuita Pietro Bovati, "restablece la verdad y la justicia" 4 mediante una sentencia determinada. La segunda, en cambio, consiste en una confrontación o litigio sin juez de por medio y donde los sujetos involucrados, a menudo familiares, solucionan el conflicto en base al amor y la sabiduría del ofendido, quien busca perdonar a su contraparte para de esta manera salvarla y, de paso, recomponer sanamente la relación quebrada. Sin embargo, Kafka-que era judío y conocía, por lo mismo, la torah- no aplica ninguno de estos modelos de penalización en su relato, puesto que estos operan, por fuerza, como reacción a un incumplimiento en el que Gregor Samsa decididamente no incurre: hijo ejemplar, hermano cómplice, empleado responsable si bien poco exitoso, no podría estar más ajeno a la rebeldía o el pecado.

¿Qué es, entonces, lo que justifica tanto padecimiento? ¿Es acaso la sola existencia un peso y un castigo? ¿Cabe suponer en Kafka una perspectiva así de sombría sobre la vida? Visto así, e insistiendo en la tesis del testimonio personal, alguien podría preguntarse: ¿por qué el autor no se suicidó? En ese caso, habríamos de aventurar dos explicaciones que se complementan entre sí y no resultan del todo descabelladas: primero, Franz Kafka murió a los cuarenta y un años de tuberculosis y, por lo tanto, no sufrió una vida excesivamente larga; segundo, pertenecía a una religión en la que dicho acto era impensado: si llegó a considerar el suicidio, también tuvo en cuenta las consecuencias de ello en su familia y, por decirlo así, en su alma. De todos modos, esto es un tanto exagerado e implica volver al ya instalado perfil del hombre sumido en la angustia al que no queremos suscribir. Sin ir tan lejos, sí podemos deslizar lo siguiente: tanto en Kafka como en Samsa la actividad laboral es ejercida sin mayor entusiasmo, y bastante se ha escrito hasta ahora acerca de la raíz etimológica de la palabra trabajo en tanto tortura o, más exactamente, castigo.

\footnotetext{
${ }^{4}$ Bovati, Pietro. Giustizia e ingiustizia nell'Antico Testamento. Roma, PIB, 1994, p. 15.
} 


\section{LA CONDENA EN UN RINCÓN}

Dicho lo anterior, ya es momento de fijar lo que, a nuestro juicio, constituye más profundamente el castigo al que es sometido el personaje central de la narración: la falta de libertad. Tal como sostuvimos al inicio de este ensayo, los episodios que van sucediéndose a lo largo de las páginas son todos efectos directos de un primer evento sorpresivo frente al cual no cabe más alternativa que vivir paciente y resignadamente. Víctima, efectivamente, de las circunstancias, Gregor Samsa se encuentra preso dentro de su cuerpo y confinado en el espacio al que su familia lo relegó: una habitación que, poco a poco, va convirtiéndose en una suerte de bodega a la que van a dar objetos que significan, como el protagonista, un estorbo. No obstante, ello no equivale necesariamente a que este último sea arrastrado por la fuerza de un destino particular. Jordi Llovet, autor del ya citado prólogo a la versión de la que aquí hemos hecho lectura -cuyo título, dígase de paso, es La transformación y no La metamorfosis- vincula tal idea al cambio de nombre del relato al indicar que este no calza con

"una historia de corte mitológico como lo eran las leyendas de la Antigüedad perfiladas de acuerdo con el patrón literario que les correspondía, es decir, de acuerdo con la ley de un destino inevitable, anclada en una dimensión anacrónica y con un alcance propiamente metahistórico. Todo lo contrario: La transformación es la historia muy cotidiana y en cierto modo muy real -situada en el extremo opuesto de toda literatura con énfasis en la materia épica- de un individuo, Gregor Samsa, que se levanta, un día cualquiera de su vida rutinaria y sin grandes sobresaltos, transformado en un escarabajo" 5 .

En ese sentido, la vida de Samsa de súbito se ve a sí misma atrapada bajo el peso de un absurdo estrictamente doméstico, lo cual está reforzado en el hecho de que jamás, en toda la obra, abandona el departamento en que habita.

Debe añadirse que, junto a la incontrarrestable dirección de los sucesos, nuestro bicho raro enfrenta un progresivo despojamiento de su identidad, y con esto no nos referimos, únicamente, a la transmutación de su cuerpo, sino que, también, al cambio de su voz -si bien su madre, al principio, parece comprender sus primeras frases durante la mañana que da pie a la historia-, la pérdida de sus muebles, el debilitamiento de sus fuerzas y, en fin, un proceso de alienación cuyo reflejo fundamental, como es absolutamente obvio, está en su paso de persona a escarabajo. Más aún; cerca ya del final, una vez que Gregor perturba con su presencia a los tres huéspedes externos, sus cercanos determinan, en voz de la hermana, que ha dejado de ser el miembro de la familia que fue, y que, considerando el extremo al que se ha llegado, están obligados a deshacerse de él: es el instante en que le toca morir. El hijo y hermano ha oído la conversación y da media vuelta. Kafka, de forma extraordinaria, narra en este punto la conclusión -y el alivioluego de tanto padecer, con palabras que a él mismo afectaron enormemente:

\footnotetext{
${ }^{5}$ KAFKA, Franz. op. cit. (n. 2), p. 7.
} 
“¿Y ahora?', se preguntó Gregor mirando la oscuridad que lo rodeaba. Pronto descubrió que ya no podía moverse en absoluto. Y no se sorprendió, más bien le pareció antinatural que hasta entonces hubiera podido desplazarse con esas patitas tan delgadas. Por lo demás, se sentía relativamente a gusto. Cierto es que le dolía todo el cuerpo, pero era como si esos dolores pudiesen debilitarse gradualmente hasta acabar desapareciendo del todo. Apenas sentía ya la manzana podrida en su espalda y la inflamación de alrededor, cubiertas ambas por una fina capa de polvo. Pensó en su familia con emoción y cariño. Su convicción de que debía desaparecer era, si cabe, más firme aún que la de su hermana. En ese estado de meditación vacía y pacífica permaneció hasta que el reloj de la torre dio las tres de la madrugada. Todavía vivió el inicio de la claridad que se expandía detrás de la ventana. Luego su cabeza se inclinó del todo sin él quererlo, y por sus orificios nasales exhaló débilmente el último aliento" 6 .

Tras esta última escena, la familia Samsa experimentará cierta tristeza -y acaso también arrepentimiento- que, con todo, pronto dará paso a un definitivo restablecimiento del curso vital. De hecho, las perspectivas que se vislumbran son bastante favorables en términos económicos e, incluso, el futuro de la hermana -en la flor de su juventud, nótese a este respecto las últimas líneas- compensa en cierta manera la pérdida de Gregor.

Tal como sucedió con "Casa tomada", célebre cuento breve de Julio Cortázar, al autor de La metamorfosis -o quizá debamos decir La transformación- se le presentaron en un sueño pesadillesco las imágenes que posteriormente formarían parte del relato, de modo que la mayoría de sus contenidos estuvieron, en su origen, mucho más vinculados a fantasías amenazantes depositadas en un nivel inconsciente y subjetivo que a un discurso teórico cuidadosamente elaborado. Sin embargo, los críticos y lectores han construido toda clase de interpretaciones - políticas, religiosas, estéticas- a partir de ambas obras. Nosotros, por nuestra parte, tenemos suficientemente claro que apenas se trata de elucubraciones de relativa exactitud, más o menos próximas a lo que fue la real intención de sus autores en el proceso de composición. En ese sentido, cabe recordar que la nuestra no es sino una más de dichas alternativas, sin desmedro de lo cual haya a nuestra disposición argumentos sólidos que respalden las afirmaciones expuestas aquí, esto es, que el nada heroico Gregor Samsa, instrumento impotente de las rarezas que le vinieron encima, deviene en objeto castigado tanto por su inutilidad como por la incomunicación respecto a los que alguna vez fueron sus semejantes.

\section{REFERENCIAS BIBLIOGRÁFICAS}

Bovati, Pietro. Giustizia e ingiustizia nell'Antico Testamento, Roma, PIB, 1994.

KAFKA, Franz. La transformación. 1ª edición, Buenos Aires, Editorial Sudamericana, 2006, 4.

Millás, Juan José. El mundo. 1ª edición, Buenos Aires, Planeta, 2007.

${ }^{6}$ Ibid., p. 93. 